\title{
Influência da temperatura sobre o comportamento mecânico do aço inoxidável ferrítico ASTM A240 UNS S41003
}

\author{
Amanda Aparecida de Fátima Arruda ${ }^{1}$ \\ Ana Cecília de Carvalho ${ }^{1}$ \\ Rhelman Rossano Urzêdo Queiroz ${ }^{2}$ \\ Geraldo Lúcio de Faria ${ }^{1 *}$ (1)
}

\section{Resumo}

O aço inoxidável do tipo ASTM A240 UNS S41003 é comumente denominado no Brasil como 410D e no mundo como $12 \% \mathrm{Cr}$. A sua composição química relativamente simples tem feito dele uma alternativa economicamente viável para setores da indústria brasileira que antes utilizavam apenas produtos fabricados a partir de aço carbono. Nesse contexto, e considerando que existem poucos trabalhos disponíveis na literatura que tenham caracterizado o desempenho mecânico desse aço em condições que simulem diferentes cenários de aplicação, o presente estudo avaliou o efeito da temperatura sobre o comportamento em tração, impacto e fluência (Sag Test) do aço inoxidável ferrítico 410D. Dados inéditos, de grande utilidade para a avaliação do referido aço como alternativa para potenciais aplicações que sejam pretendidas, são apresentados nesse estudo.

Palavras-chave: ASTM A240 UNS S41003; 410D; Tração a quente; Transição dúctil-frágil; Fluência Sag Test.

\section{Temperature influence on the mechanical behavior of the ASTM A240 UNS S41003 ferritic stainless steel}

\begin{abstract}
The ASTM A240 UNS S41003 stainless steel is commonly referred to in Brazil as 410D and in the world as 12\%Cr. Its relatively simple chemical composition has made it an economically viable alternative for sectors of Brazilian industry that previously used only carbon steel products. In this context, and considering there are few available studies in the technical literature that have investigated the mechanical performance of this steel in conditions that simulate different application scenarios, the present work evaluated the effect of temperature on the tensile, impact and creep (Sag Test) behavior of the 410D ferritic stainless steel. Unpublished data, useful for the evaluation of 410D steel as an alternative material for potential intended applications, are presented in this study.
\end{abstract}

Keywords: ASTM A240 UNS S41003; 410D; Hot tensile test; Ductile-brittle transition; Creep Sag Test.

\section{Introdução}

O aço inoxidável ferrítico ASTM A240 UNS S41003 (410D) [1] tem ganhado grande destaque no Brasil. $\mathrm{O}$ referido material possui um custo relativamente baixo no mercado quando comparado a outros tipos de aços inoxidáveis em virtude de sua composição química simples. Ele foi introduzido no mercado brasileiro com o objetivo de expandir as aplicações dos aços inoxidáveis, almejando o seu emprego como substituto de alguns tipos de aços carbono em áreas onde não se justifique utilizar aços mais nobres, mas se exija bom desempenho em ambientes oxidantes e corrosivos [2-4].

Tendo em vista que o aço 410D ainda está em desenvolvimento no Brasil, poucos estudos foram feitos com foco sobre a caracterização do seu comportamento em diferentes condições de trabalho. Considerando a relevância e a atualidade do tema, alguns estudos têm sido desenvolvidos e merecem destaque, como o de Faria et al. [2] que avaliaram a possibilidade de substituição de chapas expandidas

${ }^{1}$ Departamento de Engenharia Metalúrgica e de Materiais, Universidade Federal de Ouro Preto - UFOP, Ouro Preto, MG, Brasil.

${ }^{2}$ Instituto Federal de Minas Gerais, Campus Ouro Preto, Ouro Preto, MG, Brasil.

*Autor correspondente: geraldolfaria@yahoo.com.br 
fabricadas a partir de aços comuns, por outras com menor espessura e manufaturadas com o aço 410D. Os autores, após estabelecerem critérios de comparação e avaliarem o desempenho mecânico dos diferentes produtos, concluíram que a substituição é tecnicamente viável [2-4].

Carvalho et al. [5] avaliaram a susceptibilidade à corrosão intergranular do aço 410D. Os autores concluíram que o aço sofre sensitização do tipo Step quando exposto a temperaturas de até $600^{\circ} \mathrm{C}$. Além disso, eles mostraram que amostras tratadas isotermicamente a $900^{\circ} \mathrm{C}$ sofrem austenitização parcial e, portanto, após o resfriamento, apresentam uma estrutura bifásica constituída por ferrita e martensita. Segundo os autores, a $900^{\circ} \mathrm{C}$, em função da maior solubilidade de carbono na austenita formada, não há expressiva fração de carbonetos de cromo, o que diminuiu a sua susceptibilidade à sensitização.

Arruda et al. [6] estudaram as características de camadas de óxidos formadas sobre a superfície de chapas do aço 410D isotermicamente tratadas em atmosfera oxidante. Segundo os autores, para determinadas condições de tratamento isotérmico a $900^{\circ} \mathrm{C}$, há a formação preferencial de uma camada rica em $\mathrm{Cr}_{2} \mathrm{O}_{3}$, pouco porosa e muito aderente ao substrato, com potencial para atuar como uma camada superficial protetora, melhorando o desempenho em desgaste do material [6]. Vilela et al. [7], avaliaram, por meio de simulação computacional no equilíbrio e de ensaios dilatométricos, as temperaturas críticas de transformação de fase do aço 410D no aquecimento e no resfriamento, comprovando as observações de Carvalho et al. [5]. O efeito da taxa de resfriamento sobre a cinética de transformação martensítica também foi caracterizado, gerando dados inéditos e de relevância para a adequação do processamento dessa liga [7].
Apresentada a relevância atual do aço inoxidável ferrítico ASTM A240 UNS S41003 [1] e considerando o ainda pequeno volume de trabalhos disponíveis na literatura a respeito do seu desempenho mecânico em diferentes cenários, esse trabalho, ineditamente, avaliou a influência da temperatura de trabalho sobre o seu comportamento mecânico em tração, impacto Charpy subsize e fluência (Sag Test).

\section{Materiais e métodos}

\subsection{Materiais}

O material estudado neste trabalho é um aço inoxidável ferrítico do tipo ASTM A240 UNS S41003, produzido e denominado como 410D pela Aperam South América. A composição química do aço é apresentada na Tabela 1. As amostras utilizadas no presente estudo são provenientes de uma chapa com espessura de $6 \mathrm{~mm}$ laminada à quente e recozida. A Figura 1 apresenta a microestrutura do aço estudado no estado de entrega, atacada eletroliticamente com reativo à base de ácido oxálico. Observa-se grãos ferríticos, e corrosão intergranular do tipo Step (ASTM A763 [8]), o que está em acordo com a rota de fabricação do produto e com as observações de Carvalho et al. [5].

\subsection{Métodos}

\subsubsection{Ensaios de tração}

Ensaios de tração a quente foram realizados utilizando-se uma máquina universal de ensaios TIME GROUP, modelo WDW-200, acoplada a uma célula de carga de 10ton., um LVDT

Tabela 1. Composição química do aço inoxidável ferrítico 410D (\% em peso)

\begin{tabular}{cccccccccccccc}
\hline Elemento & $\mathbf{C}$ & $\mathbf{C r}$ & $\mathbf{M n}$ & $\mathbf{S i}$ & $\mathbf{P}$ & $\mathbf{S}$ & $\mathbf{N i}$ & $\mathbf{N b}$ & $\mathbf{T i}$ & $\mathbf{V}$ & $\mathbf{M o}$ & $\mathbf{A l}$ & $\mathbf{N}_{2}{ }^{*}$ \\
\hline Concentração & 0,007 & 11,43 & 0,59 & 0,60 & 0,02 & 0,0005 & 0,33 & 0,015 & 0,001 & 0,03 & 0,008 & 0,002 & 119 \\
\hline
\end{tabular}

*p.p.m.

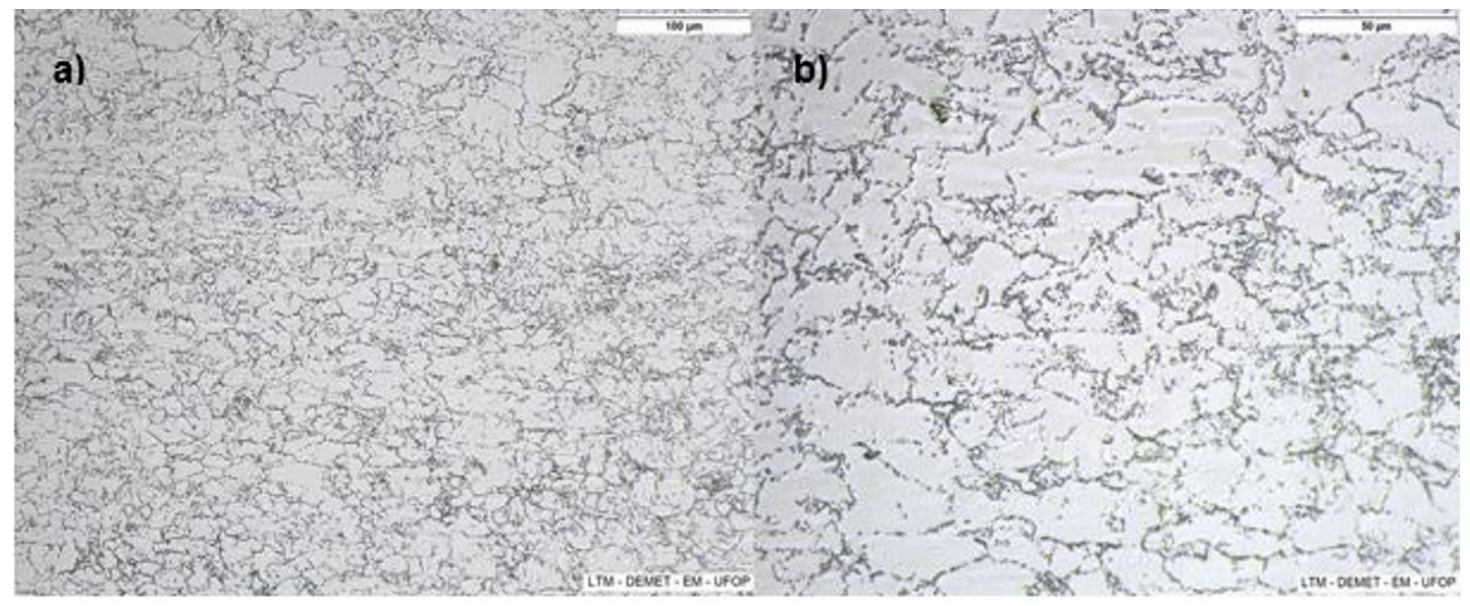

Figura 1. Microestrutura do aço 410D no estado de entrega (a) 200x (b) 500x - Ataque eletrolítico: 10V em solução aquosa de ácido oxálico 10\%. 
com resolução de $0,1 \mu \mathrm{m}$ e um forno resistivo monitorado por dois termopares (um posicionado na câmara do forno e o outro diretamente no corpo de prova). Para o controle dos parâmetros de ensaios e aquisição dos dados, foi utilizado o software WinWDC. Os ensaios foram realizados em triplicata para cada uma das temperaturas avaliadas que foram $22^{\circ} \mathrm{C}$, $300^{\circ} \mathrm{C}$ e $600^{\circ} \mathrm{C}$. O tempo de encharque de 15 minutos foi calculado em função da geometria e da massa do corpo de prova utilizado. A taxa de deformação aplicada, $10^{-3} \mathrm{~s}^{-1}$, foi definida com base em valores usuais empregados na literatura para ensaios de tração a quente [9]. Os corpos de prova ensaiados foram submetidos a análises fractográficas em um microscópio eletrônico de varredura VEGA 3 da TESCAN.

Os corpos de prova utilizados nos ensaios de tração foram usinados com as dimensões apresentadas na Figura 2, no sentido transversal ao de laminação. A região de seção reduzida, os raios de concordância e as larguras das cabeças seguiram os padrões recomendados pela norma ASTM E8M [10]. Apenas o comprimento das cabeças foi adaptado por dois motivos: i) buscando minimizar os erros nos ensaios de tração a quente, como sugere Queiroz et al. [9], não foram utilizadas as tradicionais garras cônicas "autoapertantes", mas sim garras de apoio com sistema de travamento por parafuso que exigem cabeças mais longas [9]; ii) em função das especificidades da máquina utilizada, houve a necessidade de manter uma distância de segurança entre o forno e alguns componentes da máquina, preservando-os.

\subsubsection{Ensaios de impacto}

Ensaios de impacto Charpy foram realizados em diferentes temperaturas seguindo as recomendações da norma ASTM E23 [11]. Uma máquina TIME GROUP, modelo JB-300Al/C foi utilizada. Os ensaios foram realizados nas temperaturas de $-80^{\circ} \mathrm{C},-65^{\circ} \mathrm{C},-50^{\circ} \mathrm{C}, 0^{\circ} \mathrm{C}, 24^{\circ} \mathrm{C} 150^{\circ} \mathrm{C}, 300^{\circ} \mathrm{C}$ e $600^{\circ} \mathrm{C}$ com a finalidade de obter a curva de transição dúctil-frágil do material. Para cada temperatura avaliada, o ensaio foi realizado em triplicata. Os corpos de prova utilizados foram subsize com dimensões de 55x10x5mm e entalhe de $1 \mathrm{~mm}$ posicionado no sentido transversal ao de laminação, como ilustra a Figura 3. Os corpos de prova de impacto ensaiados também foram submetidos a análises fractográficas em um microscópio eletrônico de varredura VEGA 3 da TESCAN.

\subsubsection{Ensaios de Fluência}

Os ensaios de fluência realizados nesse trabalho foram planejados segundo a metodologia Sag Test $[12,13]$. A metodologia consistiu em colocar corpos de prova planos, com dimensões padronizadas, suspensos por suportes posicionados em 4 pontos de suas extremidades em um dispositivo denominado dispositivo Sag Test, como ilustra a Figura 4. O dispositivo foi introduzido em um forno e os corpos de prova permaneceram em uma isoterma pelo intervalo de tempo desejado. Ao final do ensaio, determinou-se a flecha de fluência de cada corpo de prova, como apresenta a Figura 4c $[12,13]$.

No presente trabalho, os ensaios de fluência foram executados nas temperaturas de $900^{\circ} \mathrm{C}$ e $1000^{\circ} \mathrm{C}$, com intervalos de tempo de isoterma de 25, 50 e 100 horas para cada temperatura. Após a execução dos ensaios e medição das flechas, a caracterização microestrutural dos corpos de prova ensaiados foi feita ao longo da seção longitudinal. Perfis de microdureza Vickers também foram determinados ao longo da espessura dos corpos de prova. A distância entre indentações foi de $0,3 \mathrm{~mm}$, assim como a carga e o tempo de ensaio foram, respectivamente $200 \mathrm{gf}$ e $15 \mathrm{~s}$.

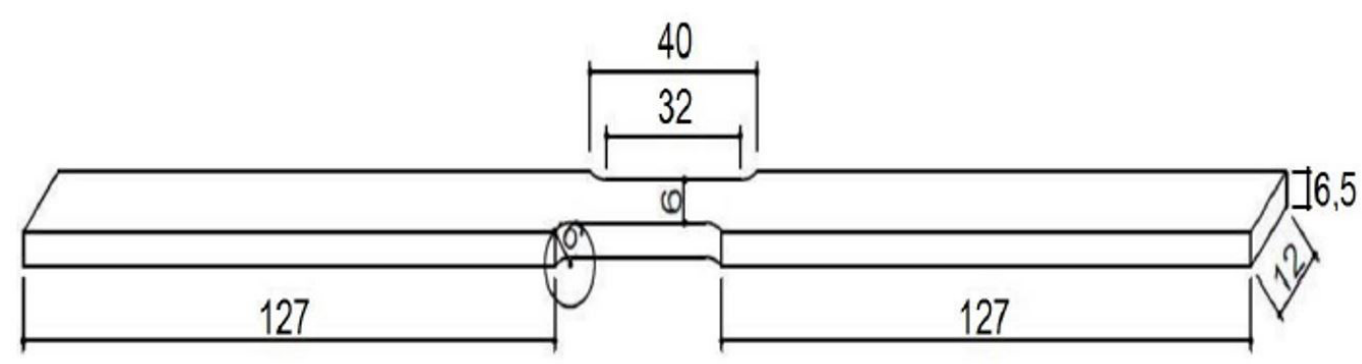

Figura 2. Figura esquemática ilustrando a geometria e as dimensões dos corpos de prova de tração utilizados (base de medida em mm).
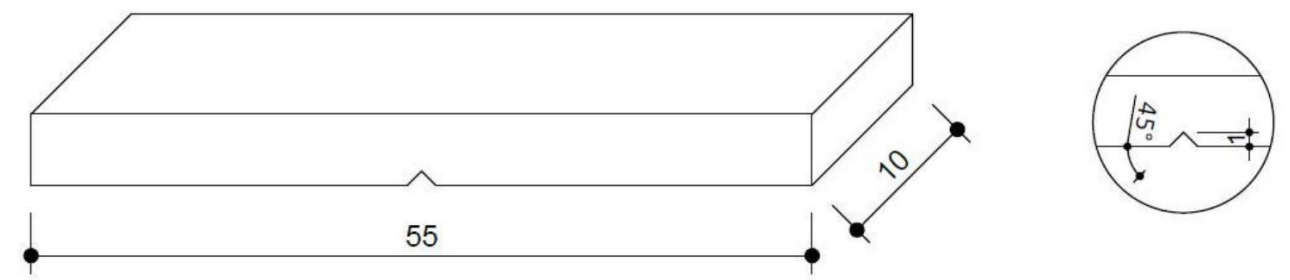

Figura 3. Figura esquemática ilustrando a geometria e as dimensões dos corpos de prova de impacto (base de medida em mm) - padrão de $5 \mathrm{~mm}$ de espessura por 10mm de largura previsto em A3.1 da norma ASTM E23 [11]. 
(a)

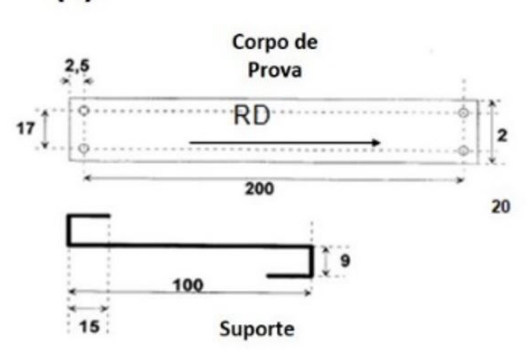

(b)

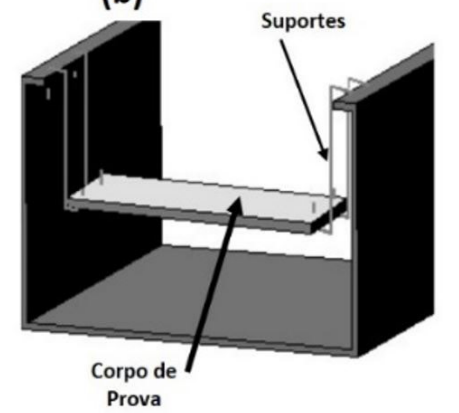

(c)

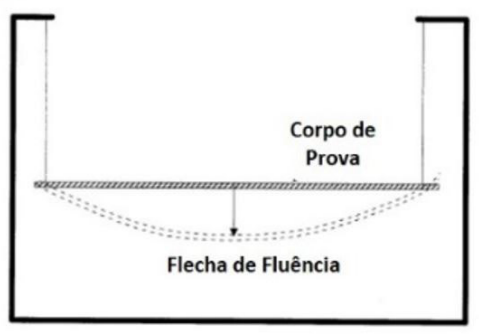

Figura 4. (a) Geometria e dimensões dos corpos de prova e dos suportes para ensaios de fluência (base de medida em mm); (b) dispositivo Sag Test com corpo de prova posicionado para o ensaio; (c) ilustração da flecha de fluência experimentada por um corpo de prova.
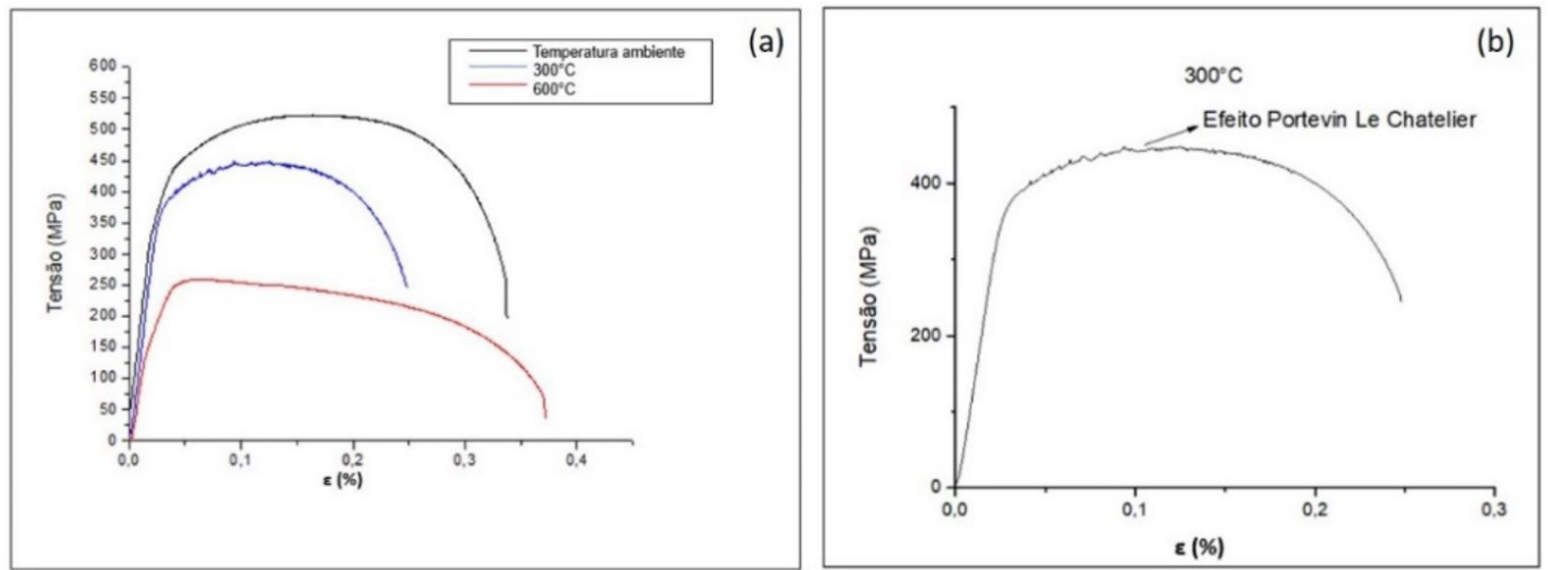

Figura 5. (a) Curvas Tensão-Deformação de engenharia do Aço Inoxidável 410D ensaiado em diferentes temperaturas; (b) Curva TensãoDeformação do Aço Inoxidável $410 \mathrm{D}$ ensaiado a $300^{\circ} \mathrm{C}$.

Tabela 2. Propriedades mecânicas do aço inoxidável 410D submetido a ensaios de tração nas temperaturas de $22^{\circ} \mathrm{C}, 300^{\circ} \mathrm{C}$ e $600^{\circ} \mathrm{C}$

\begin{tabular}{ccccc}
\hline Temperatura $\left({ }^{\circ} \mathbf{C}\right)$ & $\begin{array}{c}\text { Limite de Escoamento } \\
(\mathbf{M P a})\end{array}$ & $\begin{array}{c}\text { Limite de Resistência } \\
(\mathbf{M P a})\end{array}$ & Redução de Área (\%) & Deformação Total (\%) \\
\hline 22 & $463 \pm 6$ & $552 \pm 32$ & $66 \pm 2$ & $33,5 \pm 0,3$ \\
300 & $413 \pm 7$ & $451 \pm 5$ & $65 \pm 5$ & $26,2 \pm 0,4$ \\
600 & $256 \pm 1$ & $258 \pm 1$ & $76 \pm 2$ & $40,8 \pm 0,5$ \\
Temperatura Ambiente & Mínimo especificado: 275 & Mínimo especificado: 455 & - & - \\
(Especificação) $[1,14]$ & Típico: 400 & Típico: 490 & & \\
\hline
\end{tabular}

\section{Resultados e discussão}

\subsection{Ensaios de tração}

A Tabela 2 apresenta as principais características do aço 410D medidas em tração, assim como as suas especificações de propriedades à temperatura ambiente. Verifica-se que o aço em estudo, a $22^{\circ} \mathrm{C}$, atende às especificações mínimas para um aço da classe ASTM A240 UNS S41003 [1,14]. Observa-se que nas temperaturas de $300^{\circ} \mathrm{C}$ e $600^{\circ} \mathrm{C}$ há diminuições de $11 \%$ e $45 \%$, respectivamente, no limite de escoamento e de $18 \%$ e $35 \%$, respectivamente, no limite de resistência em relação à temperatura ambiente. No entanto, deve-se destacar que mesmo a $300^{\circ} \mathrm{C}$ o limite de escoamento do aço estudado é superior ao mínimo especificado e a $600^{\circ} \mathrm{C}$ é apenas $7 \%$ abaixo $[1,14]$.
Em relação aos indicadores de ductilidade, observa-se que há um aumento significativo do alongamento e da redução de área para os corpos de prova ensaiados a $600^{\circ} \mathrm{C}$. Este resultado obtido é consistente com os dados obtidos por Fujita et al. [15] quando estudaram aços inoxidáveis ferríticos em temperaturas elevadas. Entretanto, para os ensaios realizados a $300^{\circ} \mathrm{C}$, observou-se diminuição tanto do alongamento total quanto da redução de área em relação à condição de temperatura ambiente. Uma hipótese para explicar esse comportamento é a ocorrência do fenômeno de envelhecimento dinâmico no aço 410D nessa temperatura $[16,17]$.

A Figura 5a apresenta curvas tensão-deformação de engenharia que foram obtidas nos ensaios de tração. A Figura 5b destaca, a título de ilustração, uma curva 
obtida em um ensaio realizado a $300^{\circ} \mathrm{C}$, onde se confirma a ocorrência do fenômeno de envelhecimento dinâmico no material por meio do efeito Portervin Le Chatelier. $\mathrm{O}$ envelhecimento dinâmico tem origem no ancoramento de discordâncias em átomos de soluto durante a deformação plástica. Esse fenômeno tem sido largamente estudado por diversos autores, pois assim como observado para o aço 410D, ele é responsável por significativas alterações de comportamento mecânico. Entre elas, pode-se citar a diminuição da capacidade de deformação plástica que não pode ser desconsiderada ao se avaliar aplicações do material em temperaturas elevadas [9,16-20]. O efeito Portervin Le Chatelier se caracteriza por uma deformação descontínua que se traduz por serrilhados na região de deformação plástica uniforme da curva tensão-deformação, cuja amplitude e frequência variam com a composição química do metal e as condições experimentais $[9,16]$.

A Figura 6 apresenta fractografias das amostras submetidas aos ensaios de tração nas três temperaturas avaliadas. Observou-se que o mecanismo de fratura atuante nas três condições é o de nucleação, crescimento e coalescimento de microcavidades, indicando fraturas dúcteis, o que está em acordo com a literatura [2,21]. Destaca-se que a amostra tracionada à temperatura ambiente apresenta delaminações no sentido de laminação da chapa.
Esse fenômeno pode ser causado por inclusões alinhadas, segregação química, ou precipitação preferencial de fases no sentido de laminação decorrentes do processamento termomecânico do aço. Durante o carregamento estático, essas regiões, como forma de promover alívio de tensões, propagam trincas secundárias [2,21]. Observa-se que a $600^{\circ} \mathrm{C}$ as microcavidades se apresentam maiores do que a $300^{\circ} \mathrm{C}$, o que está coerente com o maior alongamento não uniforme verificado para a maior temperatura [21].

\subsection{Ensaios de impacto}

A Figura 7a apresenta o efeito da temperatura de ensaio sobre a tenacidade ao impacto do aço 410D (subsize). É possível afirmar que a faixa de temperatura onde ocorre a transição dúctil-frágil para o aço estudado está entre $-50^{\circ} \mathrm{C}$ e $-65^{\circ} \mathrm{C}$. Hibino [22] estudou o comportamento de dois aços inoxidáveis ferríticos: o UNS S41003 e o UNS S40910.

O aço inoxidável UNS S41003 apresentou transição dúctil-frágil entre $-20^{\circ} \mathrm{C} \mathrm{e}-50^{\circ} \mathrm{C}$. Apesar deste aço estudado por Hibino atender à mesma especificação química do material estudado nesse trabalho, o seu teor de carbono era superior e, como se sabe, quanto maior o teor de carbono, mais deslocada para a direita é a curva de transição dúctil-frágil

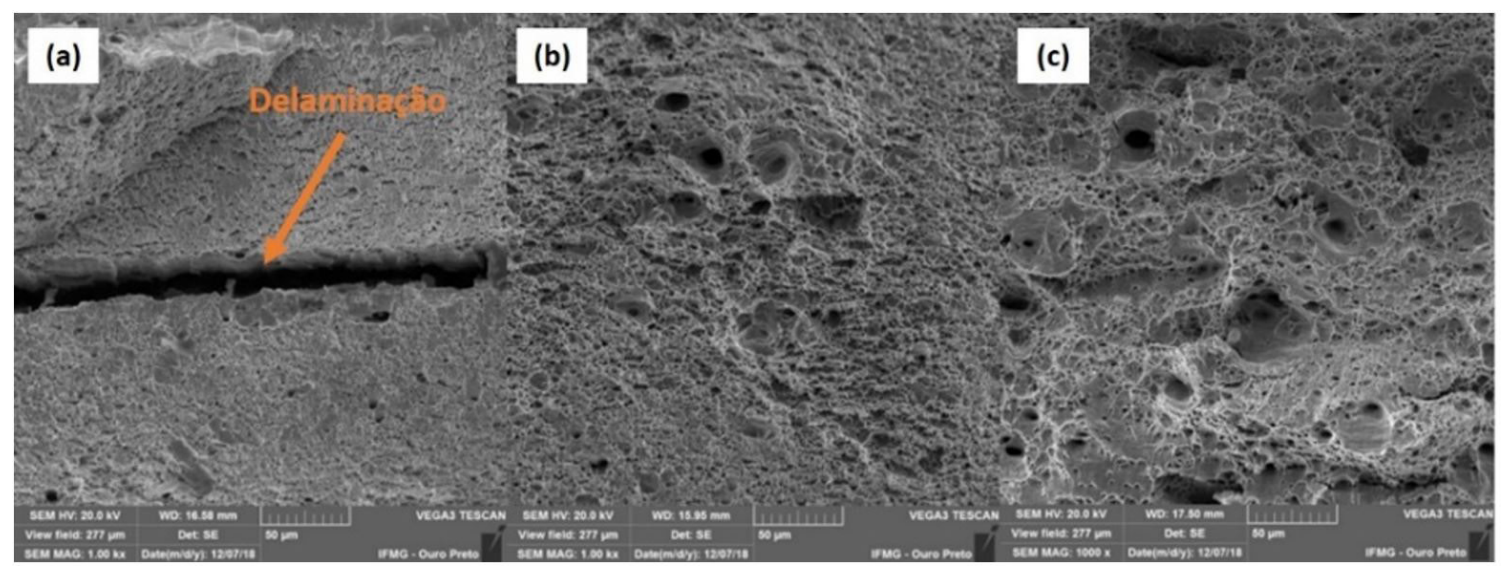

Figura 6. Fractografias ilustrando a presença de microcavidades - $1000 \mathrm{X}-$ (a) $22^{\circ} \mathrm{C}$, (b) $300^{\circ} \mathrm{C}$, (c) $600^{\circ} \mathrm{C}$.
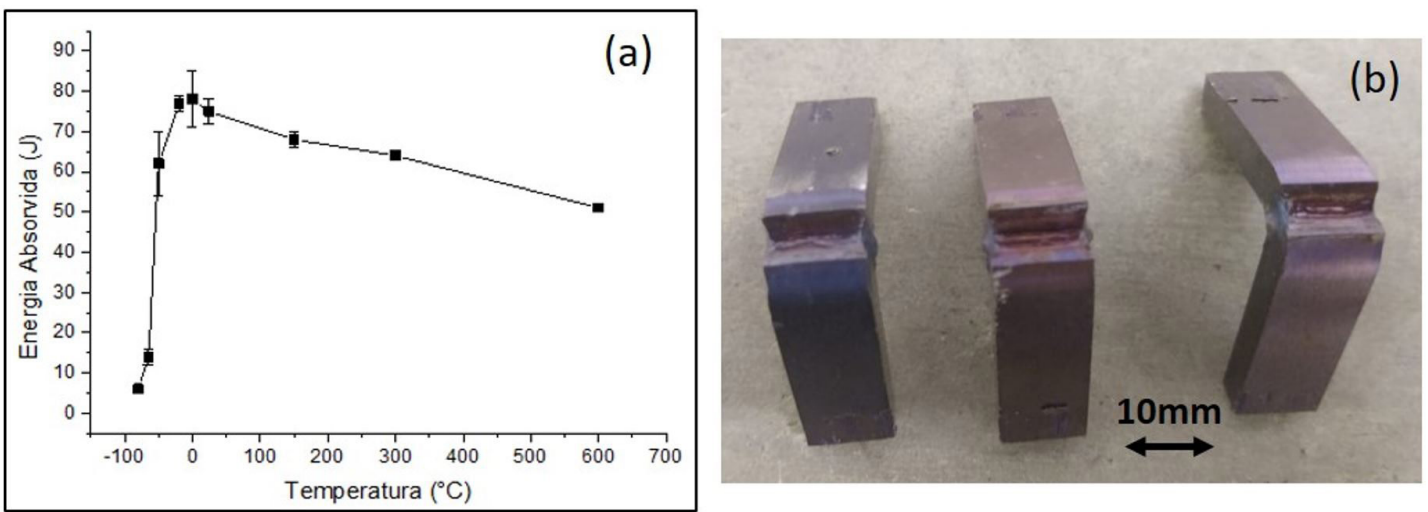

Figura 7. (a) Curva de transição dúctil-frágil do aço inoxidável ferrítico 410D; (b) Corpos de provas dos ensaios de impacto realizados à $600^{\circ} \mathrm{C}$. 
dos aços ferríticos [23,24]. Já o aço UNS S40910, apesar de ser estabilizado, apresentou transição acima de $0^{\circ} \mathrm{C}$ [22].

Observa-se ainda que para temperaturas acima de $150^{\circ} \mathrm{C}$, a energia absorvida também diminui em relação à temperatura ambiente, porém em menor magnitude. Isso ocorre devido à susceptibilidade do aço ao envelhecimento dinâmico, como já discutido. Na temperatura de $600^{\circ} \mathrm{C}$ observa-se uma diminuição mais significativa da tenacidade ao impacto que se deve ao fenômeno de fragilização azul. A Figura $7 \mathrm{~b}$ apresenta os corpos de prova ensaiados a $600^{\circ} \mathrm{C}$. Pode-se observar a formação de uma camada de óxidos azulada que recobre as superfícies de fratura, sendo essa mais uma evidência do fenômeno.

A Figura 8 apresenta as superfícies de fratura dos corpos de prova ensaiados. Para as temperaturas de $-80^{\circ} \mathrm{C} \mathrm{e}-50^{\circ} \mathrm{C}$ observou-se a presença majoritária de facetas de clivagem, destacando o aspecto frágil da fratura. Nas temperaturas $24^{\circ} \mathrm{C}$, $300^{\circ} \mathrm{C}$ e $600^{\circ} \mathrm{C}$ verificou-se a presença de microcavidades (dimples), caracterizando o mecanismo de fratura como dúctil.

\subsection{Ensaios de fluência}

A Figura 9a apresenta as flechas de fluência medidas. Considerando os desvios experimentais, pode-se afirmar que há uma tendência de aumento da flecha com o aumento da temperatura e do tempo de residência no forno. A maior flecha medida foi $7,2 \mathrm{~mm}$ após $100 \mathrm{~h}$ a $1000^{\circ} \mathrm{C}$. Esse comportamento também foi observado por outros autores ao avaliarem diferentes tipos de aços inoxidáveis $[12,13]$. Em linhas gerais, a literatura afirma que o fenômeno de fluência em aços inoxidáveis pode ser controlado principalmente por dois mecanismos que são: fluência por difusão e fluência por deslizamento de discordâncias. O mecanismo de fluência por difusão é fortemente sensível ao tamanho de grão da estrutura, enquanto o mecanismo por deslizamento de discordâncias não, sendo ele fortemente dependente da mobilidade das discordâncias [13].

Para o aço inoxidável 410D, em ambas as temperaturas ensaiadas, o mecanismo de deformação por fluência atuante foi a fluência por movimento de discordâncias. Considerando a composição química simples do aço, nessas temperaturas, não há frações significativas de precipitados que atuem como barreiras efetivas para o movimento de discordâncias. Vilela et al. [7] mostraram que a pequena fração de precipitados ricos em $\mathrm{Cr}$ que existe inicialmente na estrutura é completamente dissolvida em temperaturas superiores a $770^{\circ} \mathrm{C}$, quando se inicia a formação de austenita. Faria [13] estudou o comportamento de aços ferríticos não estabilizados, monoestabilizados e biestabilizados, concluindo que em todos

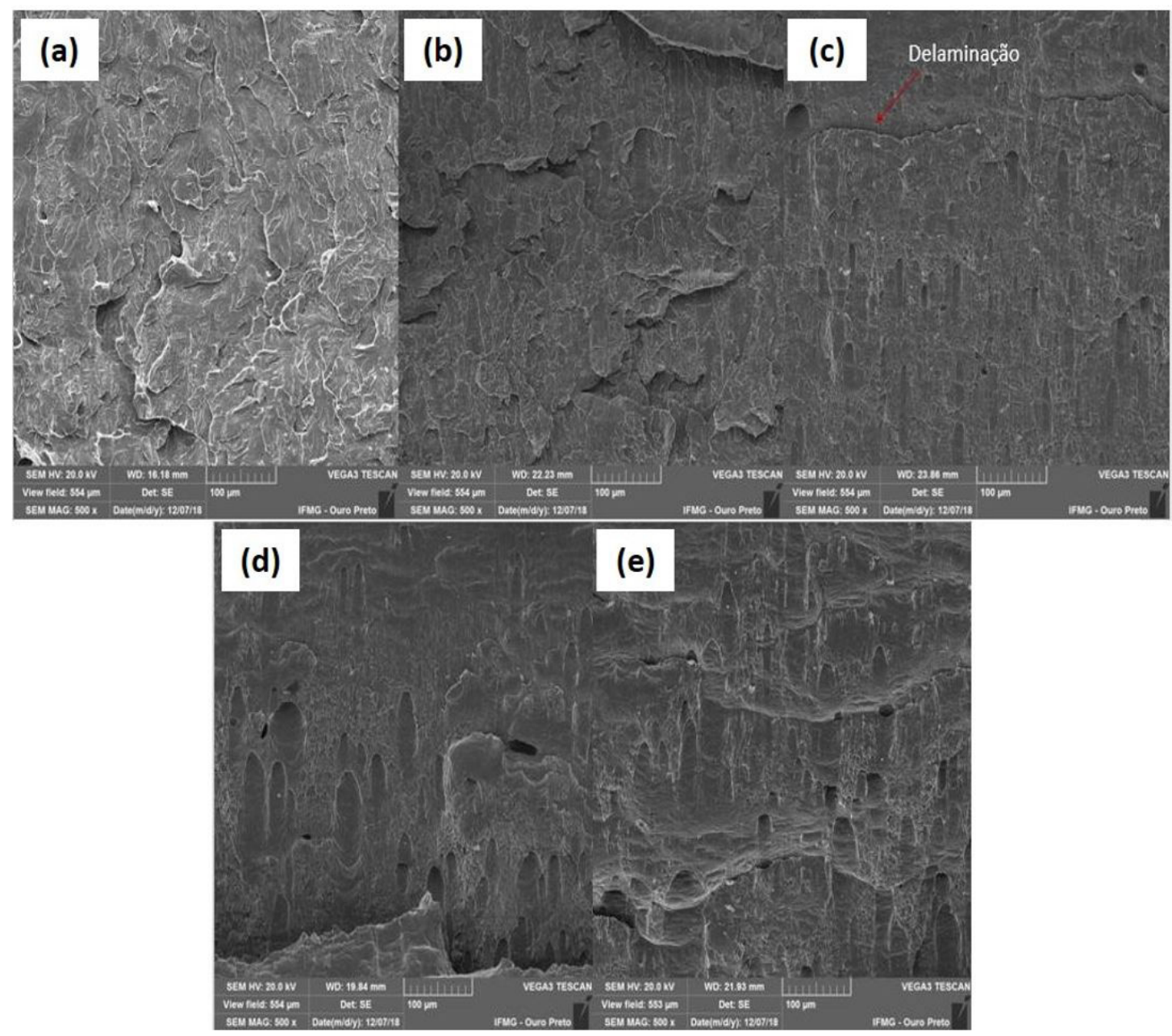

Figura 8. Fractografias dos corpos de prova de impacto ensaiados a: (a) $-80^{\circ} \mathrm{C}$; (b) $-50^{\circ} \mathrm{C}$; (c) $24^{\circ} \mathrm{C}$; (d) $300^{\circ} \mathrm{C}$; (e) $600^{\circ} \mathrm{C}-500 \mathrm{x}$. 


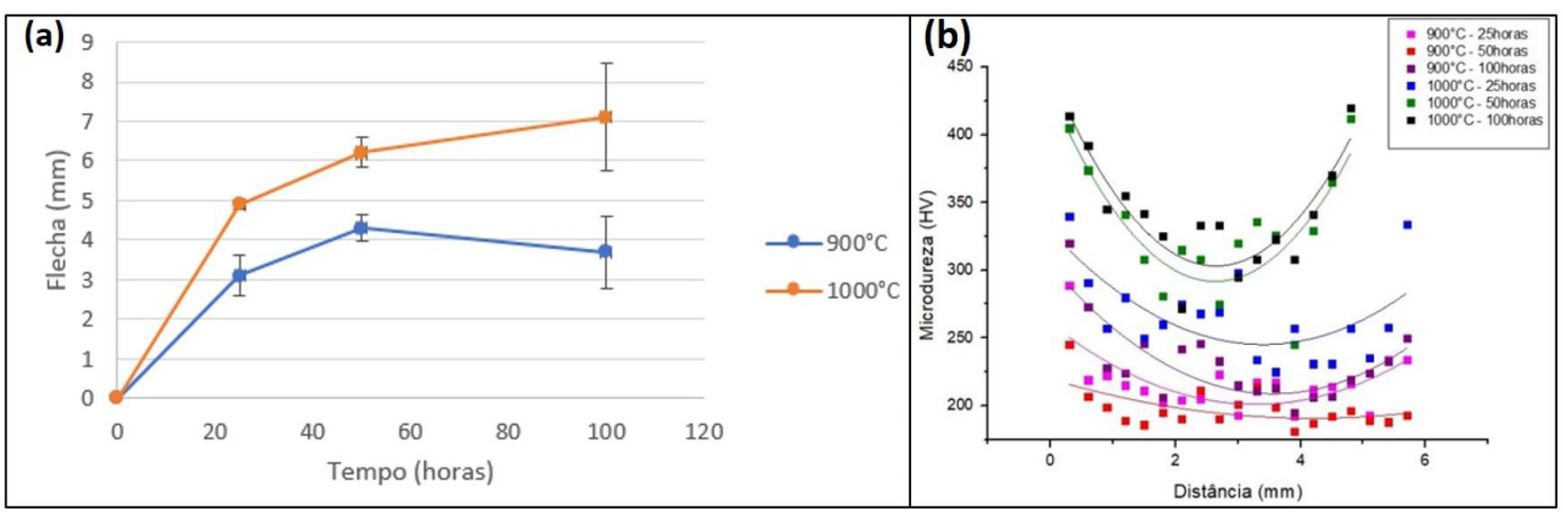

Figura 9. (a) Efeitos da temperatura e do tempo de tratamento isotérmico sobre a flecha de fluência do aço 410D; (b) Perfis de microdureza Vickers medidos ao longo da espessura dos corpos de prova ensaiados por fluência.
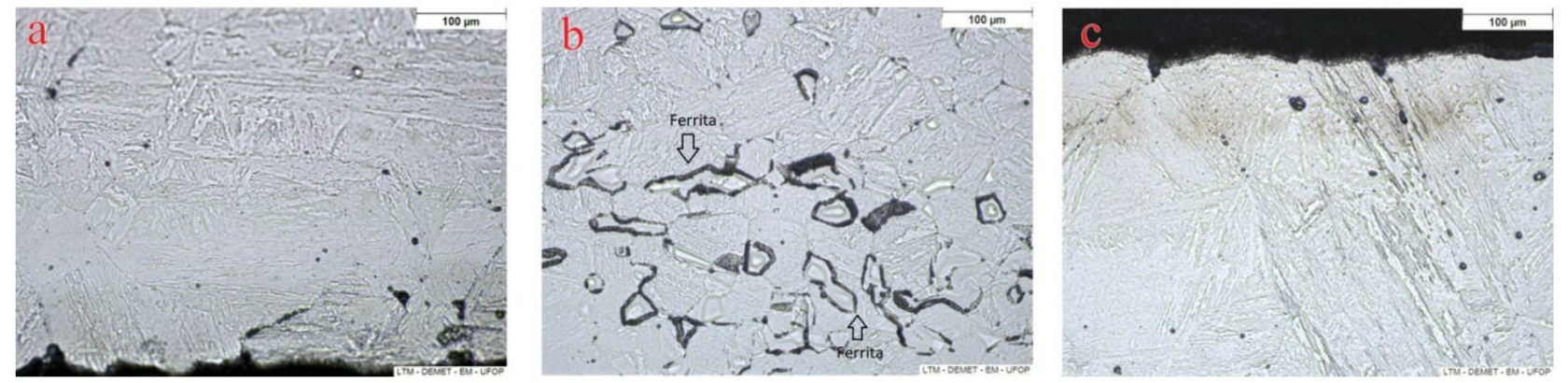

Figura 10. Microestruturas de diferentes regiões do corpo de prova ensaiado em fluência que permaneceu no forno durante 100 horas à $1000^{\circ} \mathrm{C}$ : (a) Superfície submetida a esforço compressivo; (b) centro; (c) superfície submetida a esforço trativo.

os casos, o mecanismo de deformação predominante também foi fluência por deslocamento de discordâncias em decorrência da dissolução de precipitados em temperaturas elevadas.

AFigura $9 \mathrm{~b}$ apresenta os perfis de microdureza Vickers determinados ao longo da espessura dos corpos de prova. Percebe-se uma tendência de aumento da dureza do material nas superfícies que sofreram esforços de compressão $(0$ a $3 \mathrm{~mm})$ e tração (3 a $6 \mathrm{~mm}$ ), principalmente para a temperatura de $1000^{\circ} \mathrm{C}$. Como já discutido anteriormente por Vilela et al. [7], com o aumento da temperatura e do tempo de residência do material na região intercrítica do diagrama de fases, a microestrutura do corpo de prova de fluência será bifásica (austenita-ferrita), com frações crescentes de austenita com o passar do tempo. Como as regiões submetidas aos maiores esforços trativos e compressivos experimentaram maior deformação plástica, a transformação ferrita-austenita foi catalisada. Portanto, essas regiões com maior fração de austenita, deram origem, após o resfriamento, a regiões com maior fração de martensita, justificando o incremento da dureza nas bordas. A Figura 10 apresenta evidências dessas afirmações, uma vez que é possível observar maior fração de ferrita não transformada na região central dos corpos de prova e maior fração de martensita nas bordas.

\section{Conclusões}

A respeito dos ensaios de tração a quente realizados no aço ASTM A240 UNS S41003 (410D), pode-se concluir que: 1) com o aumento da temperatura, houve diminuição significativa dos limites de escoamento e de resistência à tração; 2) na temperatura de $300^{\circ} \mathrm{Co}$ aço estudado é susceptível ao fenômeno de envelhecimento dinâmico, o que implica na diminuição de sua capacidade de deformação plástica; 3 ) nas três temperaturas de ensaio, o mecanismo de fratura predominante foi dúctil.

Sobre os ensaios de impacto, conclui-se que: 1) o aço estudado apresenta transição dúctil-frágil entre $-50^{\circ} \mathrm{C}$ e $-65^{\circ} \mathrm{C} ; 2$ ) para temperaturas acima de $-50^{\circ} \mathrm{C}$, o mecanismo de fratura predominante é dúctil; 3) o aço 410D é susceptível ao fenômeno de fragilização azul quando ensaiado a $600^{\circ} \mathrm{C}$, o que implica em diminuição da tenacidade ao impacto.

Sobre os ensaios de fluência no aço 410D, concluiu-se que: 1) existe uma tendência de aumento da flecha com o aumento da temperatura e do tempo de ensaio; 2) o mecanismo de deformação mais atuante foi a fluência por movimentação de discordâncias; 3) o aço 410D apresentou uma boa resistência à fluência nas temperaturas de $900^{\circ} \mathrm{C}$ e $1000^{\circ} \mathrm{C}$ para um aço inoxidável ferrítico não estabilizado.

\section{Agradecimentos}

À empresa Aperam South America, pelo material doado e ao CNPq (processo:303426/2017-9) pelo financiamento de Bolsas de Pesquisa. 


\section{Referências}

1 ASTM International. ASTM A240/A240M-19, Standard Specification for Chromium and Chromium-Nickel Stainless Steel Plate, Sheet, and Strip for Pressure Vessels and for General Applications. West Conshohocken, PA: ASTM International; 2019.

2 Faria GL, Godefroid LB, Menezes VS. Development of a methodology for structural and mechanical characterization of extended sheets made from stainless steels. Materials Research. 2015;18:76-82.

3 Soares HG, Faria GL. Caracterização Estrutural e Mecânica de Chapas Expandidas Confeccionadas a Partir de Aços Ferríticos. In Anais do $69^{\circ}$ Congresso Anual da ABM; 2014; São Paulo, Brasil. São Paulo: ABM; 2014.

4 Faria GL, Godefroid LB, Faria GA, Cunha EC. Avaliação da Susceptibilidade à Corrosão Intergranular em Aços Inoxidáveis Aplicados em Chapas Expandidas. In: Anais do 22 CBECIMAT; 2016; Natal, Brasil. São Paulo: ABM; 2016.

5 Carvalho AC, Faria GL, Moreira PS. Efeito do Tempo e da Temperatura de Tratamento Isotérmico Sobre o Tamanho de Grão, Dureza e Susceptibilidade à Corrosão Intergranular de um Aço Inoxidável Ferrítico. In: Anais do $78^{\circ}$ Congresso Anual da ABM; 2018; São Paulo, Brasil. São Paulo: ABM; 2018.

6 Arruda A F A, Carvalho AC, Moreira PS, Queiroz RRU, Faria G L. Características da Camada de Óxidos Formada no Aço Inoxidável 410D Após Tratamentos Isotérmicos em Atmosfera Oxidante. In: Anais do $73^{\circ}$ Congresso Anual ABM; 2018; São Paulo, Brasil. São Paulo: ABM; 2018.

7 Vilela LBM, Faria GL, Alcântara CM, Oliveira TR, Cota AB. Efeito da taxa de resfriamento sobre a formação de martensita em um aço inoxidável ferrítico com 11\%Cr e baixos teores de intersticiais. Revista Matéria. 2019;24:111.

8 ASTM International. A763-15: Standard Practices for Detecting Susceptibility to Intergranular Attack in Ferritic Stainless Steels. West Conshohocken, PA; ASTM International; 2015.

9 Queiroz RRU, Cunha FGG, Gonzalez BM. Study of dynamic strain ageing in dual phase steel. Materials Science and Engineering A. 2012;543:84-87.

10 ASTM International. E8/E8M-16a: Standard Test Methods for Tension Testing of Metallic Materials. West Conshohocken, PA; ASTM International; 2016.

11 ASTM International. E23-18: Standard Test Methods for Notched Bar Impact Testing of Metallic Materials. West Conshohocken, PA; ASTM International; 2018.

12 Cain V. High temperature creep behavior of niobium bearing ferritic stainless steels [Master thesis]. Cape Town: Cape Peninsula University of Technology; 2005.

13 Faria RA. Efeito dos elementos Ti e Nb no comportamento em fadiga dos aços inoxidáveis ferríticos utilizados no sistema de exaustão de veículos automotores [tese]. Ouro Preto: REDEMAT - Universidade Federal de Ouro Preto; 2006.

14 APERAM. 410D para taliscas de esteiras transportadoras. Biblioteca técnica. Fichas Técnicas. [acesso em 1 jun. 2019]. Disponível em: http://brasil.aperam.com/produtos/forcainox/biblioteca-tecnica/.

15 Fujita N, Ohmura K, Yamamoto A. Changes of microstructures and high temperature properties during high temperature service of a niobium added ferritic stainless steels. Materials Science and Engineering A. 2003;351:272281.

16 Srinivas NCS, Verma P, Singh V. Dynamic strain ageing behavior of modified 9Cr-1Mo steel under monotonic and cyclic loading. Advances in Materials \& Processing Technologies Conference. Procedia Engineering. 2017;184:765772 .

17 Koohbor DO, Serajzadeh IMA. Effect of rolling speed on the occurrence of strain aging durin and after warm rolling of low carbon steel. Journal of Materials Science Letters. 2010;45:3405-3412.

18 Dehghani K, Jonas JJ. Dynamic bake hardening of interstitial-free steels. Mettalurgical and Materials Transaction A. 2000; 31:1375-1384.

19 Sener B, Yurci ME. Comparison of Quase-static Constitutive Equations and Modeling of Flow Curves for Austenitic 304 and Ferritic 430 Stainless Steels. In: Special Issue of the 6th International Congress \& Exhibition; 2016; Maslak, Istanbul, Turkey. 2016.

20 Kumar MV, Balasunramanian V, Rao AG. Hot tensile properties and strain hardening behaviour of super 304HCu stainless steel. Journal of Materials Research and Technology. 2017;6(2):116-122. 
21 Faria GL, Godefroid LB, Nery FV. Damage evolution in a tensile specimen of a ductile stainless steel. Revista Escola de Minas. 2016;69:175-183.

22 Hibino AH. Estudo de tenacidade da zona termicamente afetada dos aços inoxidáveis ferríticos UNS S40910 e UNS S41003 [dissertação]. Belo Horizonte: Universidade Federal de Minas Gerais; 2011.

23 Hippert E. Investigação experimental do comportamento dúctil de aços API- X70 e aplicação de curvas de resistência JxAa para previsão de colapso em dutos [tese]. São Paulo: USP; 2004.

24 Uusikallio S, Miettunen I, Anttila S, Nevasmaa P, Manninen TP. Suitability of size adjustment in impact toughness transition region for subsized ferritic stainless steel charpy-V results. In: Conference proceedings of the 9th European Stainless Steel Conference : Science \& Market \& 5th European Duplex Stainless Steel Conference \& Exhibition - ESSC \& DUPLEX; 2017; Bergamo, Italy. 2017.

Recebido em: 28 Out. 2019

Aceito em: 16 Jul. 2020 